\title{
Selective Conversion of 2-Methylfuran to 1,4-Pentanediol Catalyzed by Bimetallic Ni-Sn Alloy
}

\section{R. Rodiansono ${ }^{*}$, Maria Dewi Astuti ${ }^{1}$, Sadang Husain ${ }^{2}$, Agung Nugroho³, S. Sutomo ${ }^{4}$}

${ }^{1}$ Department of Chemistry, Lambung Mangkurat University, Jl. A. Yani Km 36 Banjarbaru, Indonesia. ${ }^{2}$ Department of Physics, Lambung Mangkurat University, Jl. A. Yani Km 36 Banjarbaru, Indonesia. ${ }^{3}$ Department of Agro-industrial Engineering, Faculty of Agriculture, Lambung Mangkurat University, Jl. A. Yani Km 36.0 Banjarbaru South Kalimantan, Indonesia.

${ }^{4}$ Department of Pharmacy, Lambung Mangkurat University, Jl. A. Yani Km 36 Banjarbaru, Indonesia.

Received: $12^{\text {th }}$ February 2019; Revised: $26^{\text {th }}$ April 2019; Accepted: 29th April 2019; Available online: 30th September 2019; Published regularly: December 2019

\section{Abstract}

The selective conversion of 2-methylfuran (2-MeF) to 1,4-pentanediol (1,4-PeD) over bimetallic nickeltin alloy catalysts in the ethanol/ $\mathrm{H}_{2} \mathrm{O}$ solvent mixture was studied. By using bulk Ni-Sn(x); $\mathrm{x}=3.0$ and 1.5 catalysts, a maximum yield of $1,4-\mathrm{PeD}(49 \%)$ was obtained at $94 \%$ conversion of 2 -MeF. The dispersion of $\mathrm{Ni}-\mathrm{Sn}(\mathrm{x})$ on the aluminium hydroxide $(\mathrm{AlOH})$ or $\gamma-\mathrm{Al}_{2} \mathrm{O}_{3}$ supports allowed to an outstanding yield of 1,4-PeD (up to $64 \%$ ) at $433 \mathrm{~K}, 3.0 \mathrm{MPa}$ of $\mathrm{H}_{2}$ within $12 \mathrm{~h}$. Ni-Sn(3.0)/AlOH catalyst was found to be reusable and the treatment of the recovered Ni-Sn(3.0)/AlOH catalyst with $\mathrm{H}_{2}$ at $673 \mathrm{~K}$ for $1 \mathrm{~h}$ restored the catalyst's original activity and selectivity. Copyright (c) 2019 BCREC Group. All rights reserved

Keywords: Ni-Sn alloy catalysts; selective conversion; 2-methylfuran; 1,4-pentanediol; 2methyltetrahydrofuran

How to Cite: Rodiansono, R., Astuti, M.D., Husain, S., Nugroho, A., Sutomo, S. (2019). Selective Conversion of 2-Methylfuran to 1,4-Pentanediol Catalyzed by Bimetallic Ni-Sn Alloy. Bulletin of Chemical Reaction Engineering \& Catalysis, 14(3): 529-541 (doi:10.9767/bcrec.14.3.4347.529-541)

Permalink/DOI: https://doi.org/10.9767/bcrec.14.3.4347.529-541

\section{Introduction}

The catalytic transformation of biomassderived furans and their derivatives into a variety of specialty chemicals, fuel additives, and solvents have received considerable attention in the past decade as green alternatives to the petrochemicals processes [1]. Among of biomassderived furans, 2-methylfuran (2-MeF) has highly promising physical and chemical properties for application as alternative fuels or as precursor of various valuable chemical intermediates [2]. Industrial scale production of $2-\mathrm{MeF}$

* Corresponding Author.

E-mail: rodiansono@ulm.ac.id (R. Rodiansono);

Tel./fax.: +62 5114773112 had obtained via direct conversion of furfural which is in turn available on an industrial scale by the hydrolysis-dehydration of hemicellulose part of agriculture wastes and forest residues [3] by using copper-, nickel-, or palladium-based catalysts [4].

Further catalytic conversion of $2-\mathrm{MeF}$ over Pt-metal groups through furan ring hydrogenation produced the 2-methyltetrahydrofuran(2MeTHF) as the main product [5]. Aliaga et al. reported the 2-MeF hydrogenation on Pt nanocatalyst and the product selectivity was depended on the reaction temperatures, whereas the selectivities of 1-pentanol (98\%) and 2-pentanol were obtained at $313 \mathrm{~K}$ and $363 \mathrm{~K}$, respectively. They proposed that the Pt-surface catalyst and 2 -MeF interaction through heterocyclic $\pi$-cloud 
binding in nearly flat configuration; this allow ring opening, leading to the formation of pentanol isomer under mild conditions [6]. Guliants et al. also reported the deuterium-labelling study during the hydrogenation of $2-\mathrm{MeF}$ over carbon-supported $\mathrm{Pd}$ or Pt catalysts and indicated that $\mathrm{C}=\mathrm{C}$ furan ring hydrogenation occurred at low reaction temperature while $\mathrm{C}-\mathrm{O}$ bond hydrogenolysis favoured at elevated temperatures [7].

2-MeF also can be transformed into 1,4pentanediol (1,4-PeD), one of important $\alpha, \omega-$ diols through the hydrogenolysis reactions using monometalic or bimetallic heterogeneous catalysts [8] which can be used as a component of disinfectants, an ingredient of various cosmetic products, monomers of polyesters and polyurethans [9]. The synthesis of $1,4-\mathrm{PeD}$ from $2-\mathrm{MeF}$ was proposed firstly by Schniepp et al. in the presence of reduced $\mathrm{Ni}$ on Celite catalyst at $423 \mathrm{~K}, 10.3 \mathrm{MPa}$ of $\mathrm{H}_{2}$, a reaction time of 1.5 $\mathrm{h}$ and afforded a mixture of 2 -MeTHF $(30 \%$ yield), 5-hydroxy-2-pentanone (5H2PeO) $(31 \%$ yield), and 1,4-PeD (4\% yield). By changing the reaction period to $8 \mathrm{~h}$ under the similar reaction conditions, $36 \%$ yield of $2-\mathrm{MeTHF}$ and $62 \%$ yield 1,4-PeD were obtained. They proposed that $1,4-\mathrm{PeD}$ was formed through hydrolysishydrogenation of furan ring in the form of either an open-chain (5-hydroxy-2-pentanone, $5 \mathrm{H} 2 \mathrm{PeO})$ or cyclic structure (2-methyl-2hydroxy tetrahydromethylfuran, 2H2MeTHF) intermediates [10,11]. However, the addition of homogeneous acidic materials (e.g. formic acid or acetic glacial) are substantially required to obtain such of $1,4-\mathrm{PeD}$ or $5 \mathrm{H} 2 \mathrm{PeO}$, whereas the presence of acid may cause the dissolution of the active nickel metal catalyst into the reaction solution [12]. Similarly, Soos [13], Zolotarev et al. [13] and Perchenok et al. [14] have also reported the catalytic transformation of $2-\mathrm{MeF}$ into $5 \mathrm{H} 2 \mathrm{PeO}$ using alloyed nickel-chromium or nickel-aluminium catalysts and afforded $5 \mathrm{H} 2 \mathrm{PeO} 30 \%$ in yield which is subsequently hydrogenated to the final product of $1,4-\mathrm{PeD}$.

In this paper, we describe for the first the catalytic behaviour of bimetallic nickel-tin alloy both bulk and supported catalysts [15-18] in the selective conversion of $2-\mathrm{MeF}$ to 2-methyl tetrahydrofuran (2-MeTHF) and 1,4-pentanediol $(1,4-\mathrm{PeD})$. The catalytic reactions were performed in an autoclave reactor system of Taiatsu Techno (a Pyrex tube was fitted inside of a sus316 jacket to protect the vessel from corrosion in acidic media) in an ethanol $/ \mathrm{H}_{2} \mathrm{O}$ solvent mixture under mild reaction conditions (393-453 K, $23.0 \mathrm{MPa}$, and $12 \mathrm{~h}$ ).
The effects of solvent use, various bimetallic $\mathrm{Ni}$-Sn alloy catalysts with different $\mathrm{Ni} / \mathrm{Sn}$ molar ratios, and reaction parameters (temperatures, initial $\mathrm{H}_{2}$ pressure, time profiles, and reusability test) were investigated and discussed systematically.

\section{Materials and Methods}

\subsection{Materials}

Sodium hydroxide $(\mathrm{NaOH})(97 \%)$, nickel (II) chloride hexahydrate $\left(\mathrm{NiCl}_{2} .6 \mathrm{H}_{2} \mathrm{O}, 99.9 \%\right)$, tin (II) chloride dihydrate $\left(\mathrm{SnCl}_{2} .2 \mathrm{H}_{2} \mathrm{O}, 99.9 \%\right.$, aluminium hydroxide $(\mathrm{AlOH})$ were purchased and used as received from WAKO Pure Chemical Industries, Ltd. unless otherwise stated. $\gamma-\mathrm{Al}_{2} \mathrm{O}_{3}\left(S_{\mathrm{BET}}=100 \mathrm{~m}^{2} \mathrm{~g}^{-1}\right)$ were purchased from Japan Aerosil Co. 2methylfuran (98\% G C ), $\quad 2$ methyltetrahydrofuran ( $98 \%$ GC), 2-pentanol (98\% GC) were purchased from Tokyo Chemical Industries, Ltd. All organic chemical compounds were purified using standard procedures prior to use.

\subsection{Catalyst preparation}

A typical procedure of the synthesis of aluminium hydroxide supported nickel-tin (Ni$\mathrm{Sn}(3.0) / \mathrm{AlOH} ; \quad 3.0$ is feeding ratio) alloy catalyst is described as follows [14,17]: $\mathrm{NiCl}_{2} .6 \mathrm{H}_{2} \mathrm{O} \quad(18.0 \mathrm{mmol})$ was dissolved in deionised water (denoted as solution $\mathrm{A}$ ), and $\mathrm{SnCl}_{2} .2 \mathrm{H}_{2} \mathrm{O} \quad(6.0 \mathrm{mmol})$ was dissolved in ethanol/2-methoxy ethanol (2:1) (denoted as solution B) at room temperature. An one gram $\mathrm{AlOH}$ (aluminium hydroxide, typically bayerite type), solutions A, and B were mixed at room temperature; the temperature was subsequently raised to $323 \mathrm{~K}$ and the mixture was stirred for $12 \mathrm{~h}$. The $\mathrm{pH}$ of the mixture was adjusted to 12 through the dropwise addition of an aqueous solution of $\mathrm{NaOH}(3.1 \mathrm{M})$. The mixture was then placed into a sealed-Teflon autoclave for the hydrothermal reaction at 423 $\mathrm{K}$ for $24 \mathrm{~h}$. The resulting black precipitate was filtered, washed with distilled water, and then dried under vacuum overnight. Prior to the catalytic reaction, the obtained black powder was reduced with $\mathrm{H}_{2}$ at $673 \mathrm{~K}$ for $1.5 \mathrm{~h}$.

\subsection{Catalyst characterization}

XRD measurements were recorded on a Mac Science M18XHF instrument using monochromatic $\mathrm{Cu}-\mathrm{K} \alpha$ radiation $(\lambda=0.15418$ $\mathrm{nm})$. The XRD was operated at $40 \mathrm{kV}$ and 200 $\mathrm{mA}$ with a step width of $0.02^{\circ}$ and a scan speed 
of $4^{\circ} \cdot \min ^{-1}(\alpha 1=0.154057 \mathrm{~nm}, \alpha 2=0.154433$ $\mathrm{nm})$. ICP measurements were performed on an SPS $1800 \mathrm{H}$ plasma spectrometer of Seiko Instruments Inc. (Ni: $221.7162 \mathrm{~nm}$ and $\mathrm{Sn}: 189.898 \mathrm{~nm})$. The BET surface area $\left(S_{\mathrm{BET}}\right)$ and pore volume $\left(V_{\mathrm{p}}\right)$ were measured using $\mathrm{N}_{2}$ physisorption at $77 \mathrm{~K}$ on a Belsorp Max (BEL Japan). The samples were degassed at $473 \mathrm{~K}$ for $2 \mathrm{~h}$ to remove physisorbed gases prior to the measurement. The amount of nitrogen adsorbed onto the samples was used to calculate the Brunauer-Emmett-Teller (BET) surface area via the BET equation. The pore volume was estimated to be the liquid volume of nitrogen at a relative pressure of approximately 0.995 according to the BarrettJoyner-Halenda (BJH) approach based on desorption data [19]. SEM images of the synthesized catalysts were taken on a JEOL JSM-610 SEM microscope after the samples were coated using a JEOL JTC-1600 autofine coater. TEM image analyses were taken on Hitachi High-Tech H-7650 microcope with an emissive gun, operated at $150 \mathrm{kV}$.

The $\mathrm{H}_{2}$ uptake was determined through irreversible $\mathrm{H}_{2}$ chemisorption. After the catalyst was heated at $393 \mathrm{~K}$ under vacuum for $30 \mathrm{~min}$, it was treated at $673 \mathrm{~K}$ under $\mathrm{H}_{2}$ for 30 $\mathrm{min}$. The catalysts were subsequently cooled to room temperature under vacuum for $30 \mathrm{~min}$. The $\mathrm{H}_{2}$ measurement was conducted at $273 \mathrm{~K}$, and $\mathrm{H}_{2}$ uptake was calculated according to the method described in the literature [20].

The $\mathrm{NH}_{3}$-TPD was carried out on a Belsorp Max (BEL Japan). The samples were degassed at elevated temperature of $373-473 \mathrm{~K}$ for $2 \mathrm{~h}$ to remove physisorbed gases prior to the measurement. The temperature was then kept at $473 \mathrm{~K}$ for $2 \mathrm{~h}$, while flushed with $\mathrm{He}$ gas. $\mathrm{NH}_{3}$ gas (balanced $\mathrm{NH}_{3}, 80 \%$ and $\mathrm{He}, 20 \%$ ) was introduced at $373 \mathrm{~K}$ for $30 \mathrm{~min}$, then evacuated by helium gas to remove the physisorbed also for $30 \mathrm{~min}$. Finally, temperature programmed desorption was carried out at temperature of 373-1073 $\mathrm{K}$ and the desorbed $\mathrm{NH}_{3}$ was monitored by TCD.

\subsection{Catalytic reactions}

A typical reaction procedure of 2methylfuran $(2-\mathrm{MeF})$ hydrogenation as follows. A $1.2 \mathrm{mmol}$ of 2 -methylfuran was dissolved in $3.5 \mathrm{~mL}$ ethanol $/ \mathrm{H}_{2} \mathrm{O}$ mixture (1.5: 2.0 volume ratio) and $50 \mathrm{mg}$ of $\mathrm{Ni}-\mathrm{Sn}(3.0) / \mathrm{AlOH}$ catalyst were placed into an autoclave reactor system of Taiatsu Techno (a Pyrex tube was fitted inside of a SUS316 jacket to protect the vessel from corrosion in acidic media). After $\mathrm{H}_{2}$ was introduced into the reactor (initial $\mathrm{H}_{2}$ pressure of $3.0 \mathrm{MPa}$ ) at room temperature, the temperature of the reactor was raised to $433 \mathrm{~K}$ and the reaction time was $12 \mathrm{~h}$. In the reaction, 1,4-PeD and 2-MeTHF were mainly produced, while $2 \mathrm{H} 2 \mathrm{MeTHF}$ and 2 - $\mathrm{PeOH}$ were also detected. The used Ni-Sn(3.0)/AlOH catalyst was easily separated using either simple centrifugation (4000 rpm for $10 \mathrm{~min}$ ) or filtration, dried overnight under vacuum at room temperature, then finally reduced with $\mathrm{H}_{2}$ at $673 \mathrm{~K}$ for $1.5 \mathrm{~h}$ prior to re-usability testing.

\subsection{Product analysis}

Gas chromatography (GC) analysis of the reactant $(2-\mathrm{MeF})$ and products $(1,4-\mathrm{PeD}, 2$ $\mathrm{PeOH}, 2 \mathrm{H} 2 \mathrm{MeTHF}$, and 2-MeTHF) was performed on a Shimadzu GC-8A with a flame ionization detector equipped with a Silicone OV-101 or a Thermon 3000 packed column length $(\mathrm{m})=3.0$; inner diameter $(\mathrm{mm})=2.0$; methylsilicone from Sigma-Aldrich Co. Ltd.). Gas chromatography-mass spectrometry (GCMS) was performed on a Shimadzu GC-17B with a thermal conductivity detector equipped with an RT-bDEXsm capillary column. ${ }^{1} \mathrm{H}$ and ${ }^{13} \mathrm{C}$ NMR spectra were obtained on a JNMAL400 spectrometer at $400 \mathrm{MHz}$; the samples for NMR analysis were dissolved in chloroform$d_{1}$ with TMS as the internal standard. The products were confirmed by the a comparison of their GC retention time, mass, ${ }^{1} \mathrm{H}$ NMR and ${ }^{13} \mathrm{C}$ NMR spectra with those of authentic samples, except for 2H2MeTHF due to the limitation of commercial availability [21].

The conversion of 2-MeTF, yield and selectivity of the products were calculated according to the Equations (1-3):

$$
\begin{aligned}
& \text { Conversion }=\frac{\text { introduced mol reactant }\left(F_{o}\right) \text {-remained mol reactant }\left(F_{t}\right)}{\text { introduced mol reactant }\left(F_{o}\right)} \times 100 \% \\
& \text { Yield }=\frac{\text { mol product }}{\text { consumed mol reactant }(\Delta F)} \times 100 \% \\
& \text { Selectivity }=\frac{\text { mol product }}{\text { total mol products }} \times 100 \%
\end{aligned}
$$

where $F_{0}$ is the introduced mol reactant (2methylfuran, 2-MeF), $F_{t}$ is the remaining mol reactant, and $\Delta F$ is the consumed mol reactant (introduced mol reactant- remained mol reactant), which are all obtained from GC analysis using an internal standard technique.

\section{Results and Discussion}

\subsection{Catalyst characterizations}

Based on the ICP-AES analyses, the compo- 
sitions of the bulk and supported Ni-Sn alloys were approximately equivalent to the feeding ratios of each precursor and were reflected in the composition of each Ni-Sn alloy phase (Table 1, entries 1-4) as described previously in elsewhere [15-18]. Four types of supports (AC, $\gamma-\mathrm{Al}_{2} \mathrm{O}_{3}$, amorphous alumina (AA), and $\mathrm{AlOH}$ )

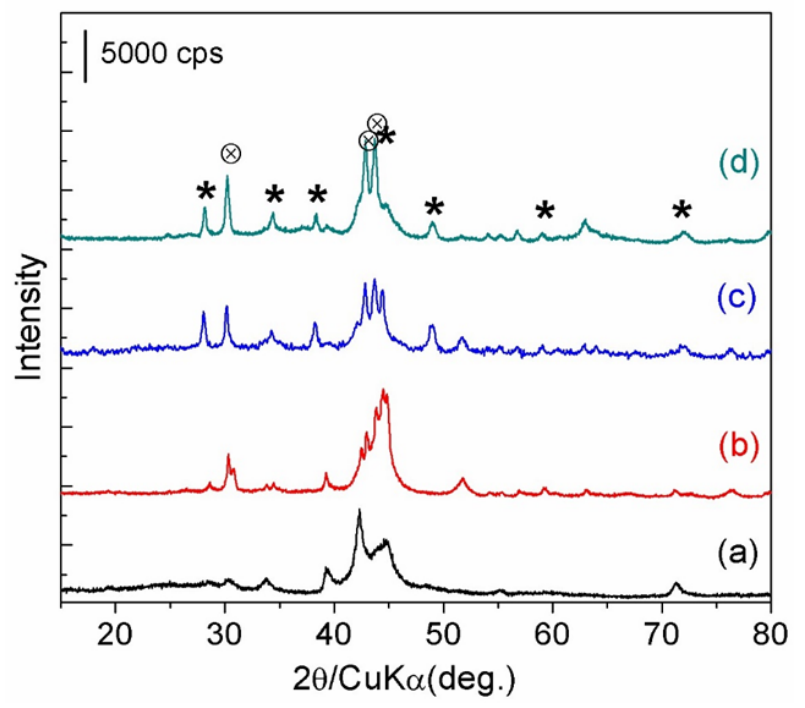

Figure 1. XRD patterns of bimetallic $\mathrm{Ni}$ $\mathrm{Sn}(3.0)$ supported on (a) Active carbon (AC), (b) amorphous alumina (AA), (c) $\gamma-\mathrm{Al}_{2} \mathrm{O}_{3}$, and (d) $\mathrm{AlOH}$ after $\mathrm{H}_{2}$ reduction at $673 \mathrm{~K}$ for $1.5 \mathrm{~h} . \otimes=$ $\mathrm{Ni}_{3} \mathrm{Sn}_{2} . *=\mathrm{Ni}_{3} \mathrm{Sn}$. were employed for the preparation of the supported Ni-Sn(3.0) alloy catalysts using a procedure similar to that used for the synthesis of the bulk phases. The physicochemical properties of the supported Ni-Sn(3.0) alloy catalysts are also summarized in Table 1 (entries 5-7), and the XRD patterns are shown in Figure 1. The total loading amount of Ni-Sn was 2.3 2.4 mmol.g- ${ }^{-1}$ (based on the ICP-AES results) for all of the supported Ni-Sn(3.0) samples (the composition (mol\%) of $\mathrm{Ni}$ and $\mathrm{Sn}$ are listed in Table 1). The $\mathrm{H}_{2}$ uptake for supported Ni-Sn(3.0) catalysts were almost twice higher than that of the bulk alloy (entries 4-7). The XRD patterns also revealed that $\mathrm{Ni}_{3} \mathrm{Sn}$ or mixture of $\mathrm{Ni}_{3} \mathrm{Sn}$ and $\mathrm{Ni}_{3} \mathrm{Sn}_{2}$, as the major alloy phases, were formed on the $\mathrm{AC}, \mathrm{AA}, \gamma-\mathrm{Al}_{2} \mathrm{O}_{3}$, and $\mathrm{AlOH}$ supports (Figure 1a-c) [22].

TEM images of supported Ni-Sn(3.0)/AA and $\mathrm{Ni}-\mathrm{Sn}(3.0) / \mathrm{AlOH}$ alloy catalysts show spherical bimetallic Ni-Sn alloy particles which are roughly dispersed on the surface of aluminium hydroxide as shown in Figure 2. The differences in particle sizes of Ni-Sn alloy were easily observed between $\mathrm{Ni}-\mathrm{Sn}(3.0) / \mathrm{AA}$ and $\mathrm{Ni}$ $\mathrm{Sn}(3.0) / \mathrm{AlOH}$ system, a larger amount of Ni-Sn alloy nanoparticles with bigger sizes were also observed in Figure 2a.

Figure 3 shows the SEM images of bulk Ni$\mathrm{Sn}(1.5)$, Ni-Sn(3.0), and supported Ni-Sn(3.0) catalysts. Scanning electron microscopy (SEM)

Table 1. Physico-chemical properties of the synthesized bulk and supported bimetallic Ni-Sn(3.0) alloy catalysts

\begin{tabular}{cllccc}
\hline Entry & Catalysts & \multicolumn{1}{c}{$\begin{array}{c}\text { Chemical composition } \\
(\mathrm{mol} \%)\end{array}$} & $\begin{array}{c}\mathrm{S}_{\mathrm{BET}^{\mathrm{c}}} \\
\left(\mathrm{m}^{2} \cdot \mathrm{g}^{-1}\right)\end{array}$ & $\begin{array}{c}\text { Amount of acid } \\
\text { sites }^{\mathrm{d}}(\mu \mathrm{mol} / \mathrm{g})\end{array}$ & $\begin{array}{c}\mathrm{H}_{2} \mathrm{e} \\
\left(\mu \mathrm{molg}^{-1}\right)\end{array}$ \\
\hline 1 & $\mathrm{Ni}-\mathrm{Sn}(0.75)$ & $\mathrm{Ni}_{42.7} \mathrm{Sn}_{57.3}\left(87 \% \mathrm{Ni}_{3} \mathrm{Sn}_{4}\right)^{f}$ & 57 & - & 4.7 \\
2 & $\mathrm{Ni}-\mathrm{Sn}(1.5)$ & $\mathrm{Ni}_{59.9} \mathrm{Sn}_{40.1}\left(91 \% \mathrm{Ni}_{3} \mathrm{Sn}_{2}\right)^{f}$ & 12 & - & 8.6 \\
3 & $\mathrm{Ni}-\mathrm{Sn}(3.0)$ & $\mathrm{Ni}_{74.9} \mathrm{Sn}_{25.1}\left(66 \% \mathrm{Ni}_{3} \mathrm{Sn}\right)^{f}$ & 6 & - & 12.0 \\
4 & $\mathrm{Ni}-\mathrm{Sn}(3.0) / \mathrm{AlOH}$ & $\mathrm{Ni}_{74.9} \mathrm{Sn}_{25.1}$ & 120 & 491 & 27.1 \\
5 & $\mathrm{Ni}-\mathrm{Sn}(3.0) / \mathrm{AC}$ & $\mathrm{Ni}_{74.9} \mathrm{Sn}_{25.1}$ & 557 & 83 & 31.2 \\
6 & $\mathrm{Ni}-\mathrm{Sn}(3.0) / \gamma-\mathrm{Al}_{2} \mathrm{O}_{3}$ & $\mathrm{Ni}_{74.9} \mathrm{Sn}_{25.1}$ & 122 & 446 & 29.8 \\
7 & $\mathrm{Ni}-\mathrm{Sn}(3.0) / \mathrm{AA}$ & $\mathrm{Ni}_{44.0} \mathrm{Sn}_{14.9} \mathrm{Al}_{41.1}$ & 122 & 473 & 32.7 \\
8 & $\mathrm{R}-\mathrm{Ni} / \mathrm{AlOH}$ & $\mathrm{Ni}_{47.6} \mathrm{Al}_{52.4}$ & 151 & 474 & 104 \\
9 & $\mathrm{Raney}{ }^{\circledR N i}$ & $\mathrm{Ni}_{86.4} \mathrm{Al}_{13.6}$ & 66 & $195^{h}$ & 121 \\
10 & $\gamma-\mathrm{Al}_{2} \mathrm{O}_{3}$ & - & 120 & $180^{i}$ & - \\
\hline
\end{tabular}

${ }^{a}$ The value in the parenthesis is Ni/Sn ratio. ${ }^{b}$ Determined by ICP-AES. ${ }^{c}$ BET specific surface areas, determined by $\mathrm{N}_{2}$ physisorption at $77 \mathrm{~K}$. ${ }^{d}$ Amount of acidic sites $\left(\mu \mathrm{mol} \mathrm{g}{ }^{-1}\right.$ ) was derived from $\mathrm{NH}_{3}$-TPD spectra. ${ }^{e} \mathrm{H}_{2}$ uptake at $273 \mathrm{~K}$ (noted after corrected for physical and chemical adsorption). fBased on the crystallographic databases and mol\% of alloy component was calculated by Multi-Rietveld Analysis Program LH-Riet 7.00 method on the Rietica software [22,23] as described previously in elsewhere [15]. sThe catalyst was synthesized from Raney nickel supported on aluminium hydroxide (R-Ni/AlOH) and tin (II) dihydrate via hydrothermal at $425 \mathrm{~K}$ for $2 \mathrm{~h}$, dried at room temperature, then followed by $\mathrm{H}_{2}$ reduction at $673 \mathrm{~K}$ for $1.5 \mathrm{~h}$ according to reference [16,17]. $h$ Reference [26]. $i$ Reference [27]. 

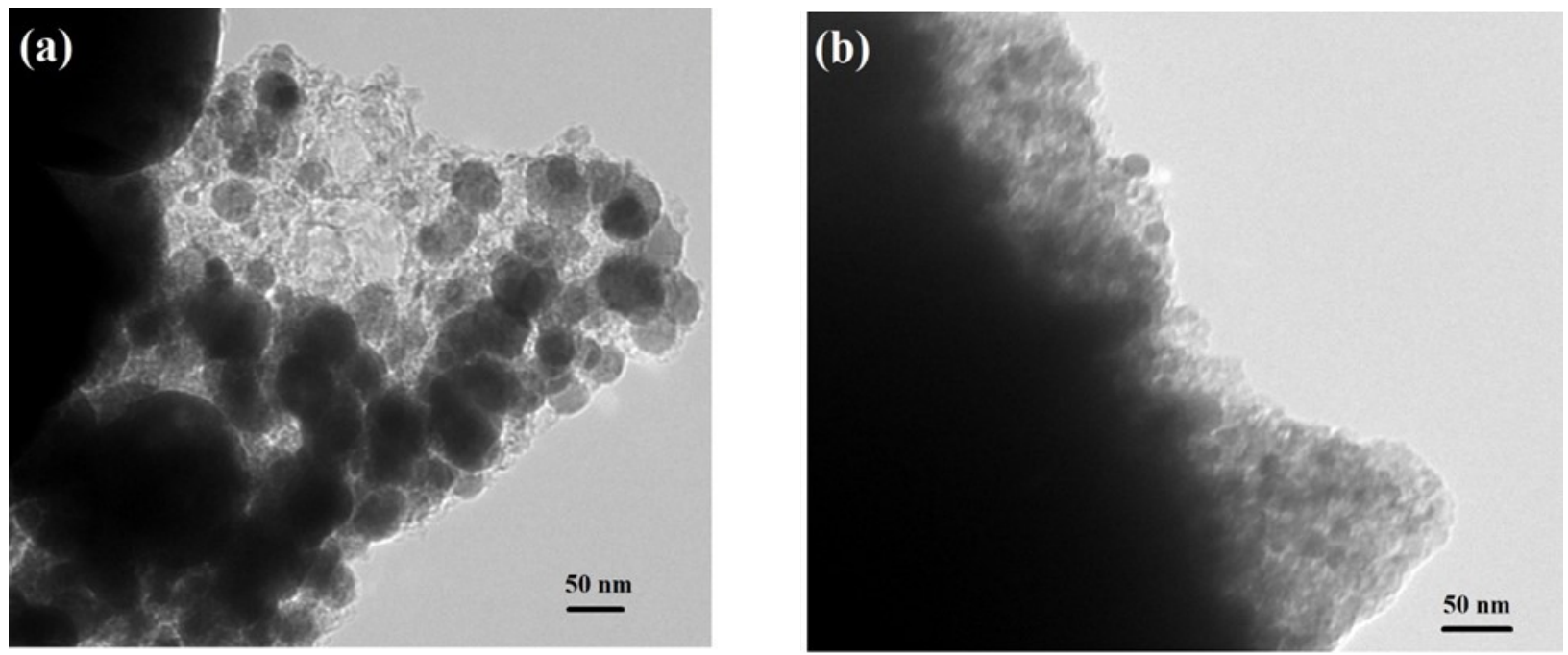

Figure 2. TEM images of (a) Ni-Sn(3.0)/AA and (b) Ni-Sn(3.0)/AlOH after reduction with $\mathrm{H}_{2}$ at $673 \mathrm{~K}$ for $1.5 \mathrm{~h}$.
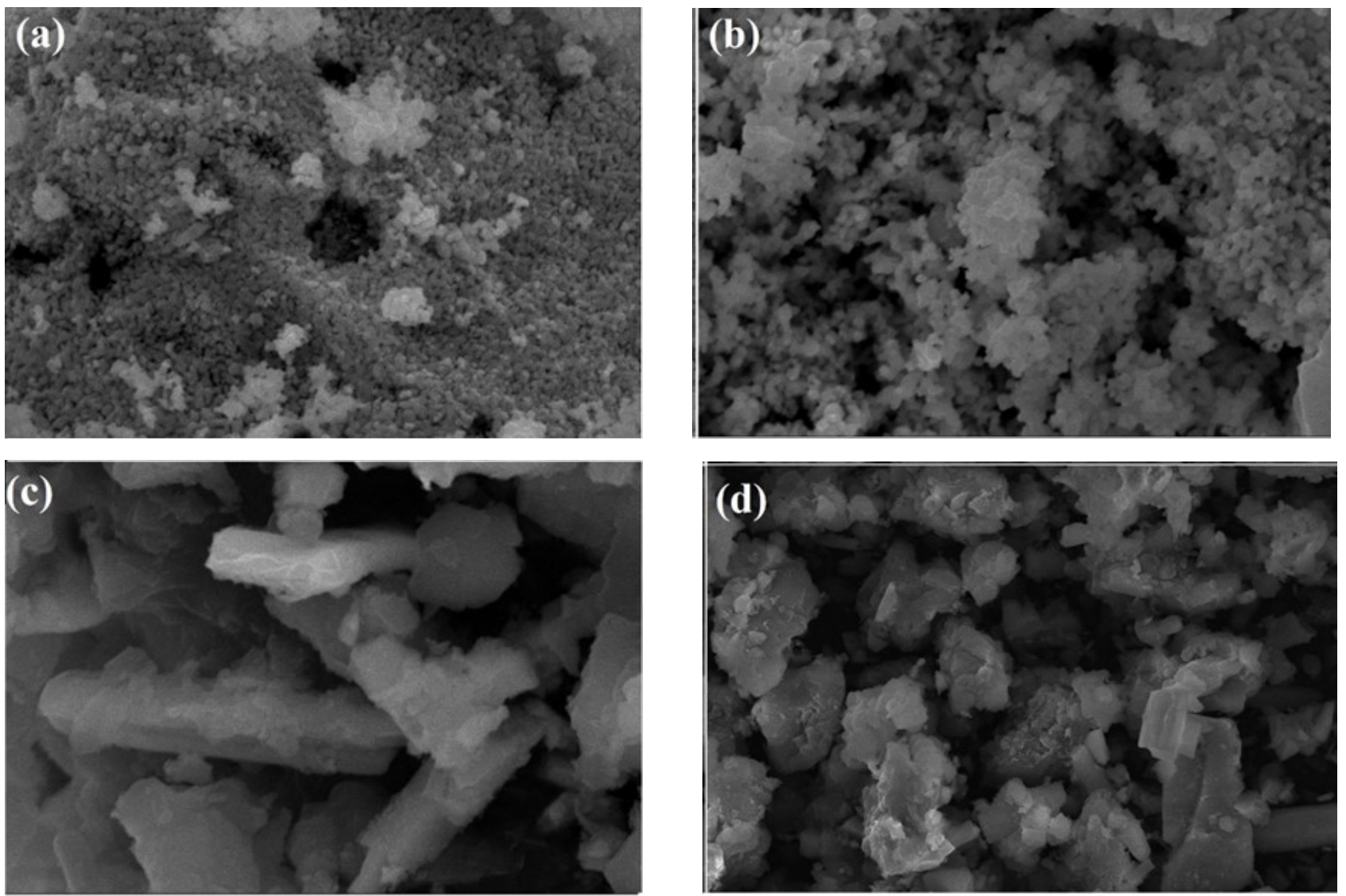

Figure 3. SEM images of (a) bulk Ni-Sn(1.5), (b) bulk Ni-Sn(3.0), (c) Ni-Sn(3.0)/AA and (d) Ni$\mathrm{Sn}(3.0) / \mathrm{AlOH}$ after reduction with $\mathrm{H}_{2}$ at $673 \mathrm{~K}$ for $1.5 \mathrm{~h}$. 
images for the bulk Ni-Sn(1.5), Ni-Sn(3.0), Ni$\mathrm{Sn}(3.0) / \mathrm{AA}$, and $\mathrm{Ni}-\mathrm{Sn}(3.0) / \mathrm{AlOH}$ revealed that the morphological differences between the bulk $\mathrm{Ni}-\mathrm{Sn}(1.5)$, Ni-Sn(3.0) and supported Ni-Sn(3.0) samples are readily visible. Note that the morphologies of bulk Ni-Sn (1.5) and Ni-Sn(3.0) are similar. Figure $3 \mathrm{a}$ shows that the bulk $\mathrm{Ni}$ $\operatorname{Sn}(1.5)$ catalyst has a relatively flat surface. Figure $3 \mathrm{~b}$ shows that unlike the smooth surface of $\mathrm{Ni}-\mathrm{Sn}(1.5)$, the surface bulk $\mathrm{Ni}-\mathrm{Sn}(3.0)$ is relatively high fragmentized. On the other hand, the spongy morphology of Ni, the Al-rich region contains hexagonal prismatic rods which are characteristic morphologies of gibbsite and bayerite, respectively, are clearly observed over $\mathrm{Ni}-\mathrm{Sn}(3.0) / \mathrm{AA}$, and $\mathrm{Ni}-\mathrm{Sn}(3.0) / \mathrm{AlOH}$ samples as shown in Figures 3c-d [24,25].

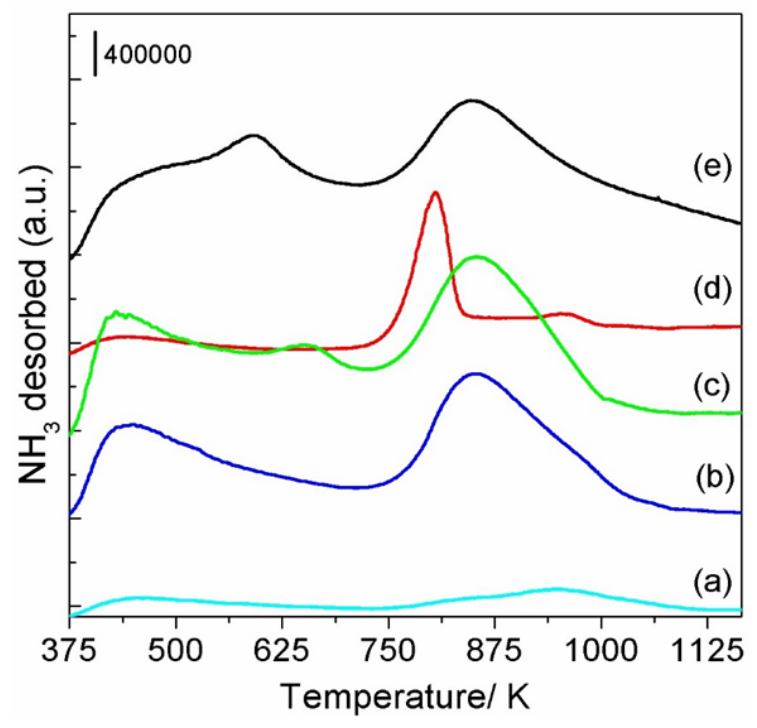

Figure 4. $\mathrm{NH}_{3}-\mathrm{TPD}$ profiles of (a) $\mathrm{Ni}$ $\mathrm{Sn}(3.0) / \mathrm{AC}, \quad$ (b) $\mathrm{Ni}-\mathrm{Sn}(3.0) / \gamma-\mathrm{Al}_{2} \mathrm{O}_{3}$, (c) Ni$\mathrm{Sn}(3.0) / \mathrm{AA}$, (d) $\mathrm{Ni}-\mathrm{Sn}(3.0) / \mathrm{AlOH}$ catalysts after $\mathrm{H}_{2}$ reduction at 673 for $1.5 \mathrm{~h}$, and (e) $\mathrm{R}$ $\mathrm{Ni} / \mathrm{AlOH}$ catalyst.
The acid density of each synthesized supported $\mathrm{Ni}-\mathrm{Sn}(3.0)$ alloy catalyst was measured by using ammonia $\left(\mathrm{NH}_{3}\right)$ as molecular probe as shown in Figure 5 and the results are also summarized in Table 1.

The acidities of the supported $\mathrm{Ni}-\mathrm{Sn}(3.0)$ alloy catalysts were measured by $\mathrm{NH}_{3}$-TPD and the profiles are shown in Figure 4. Generally, the $\mathrm{NH}_{3}$-TPD profiles of aluminium hydoxide $(\mathrm{AlOH})$, gamma-alumina $\left(\gamma-\mathrm{Al}_{2} \mathrm{O}_{3}\right)$, and ammorphous alumina (AA) supported $\mathrm{Ni}$ $\mathrm{Sn}(3.0)$ has a good similarity and are likely due to great contribution of aluminium oxide or aluminium hydroxide of support (Figures $4 \mathrm{~b}$-e). The total acidity of each catalyst is estimated from the desorbed amount of $\mathrm{NH}_{3}$ without

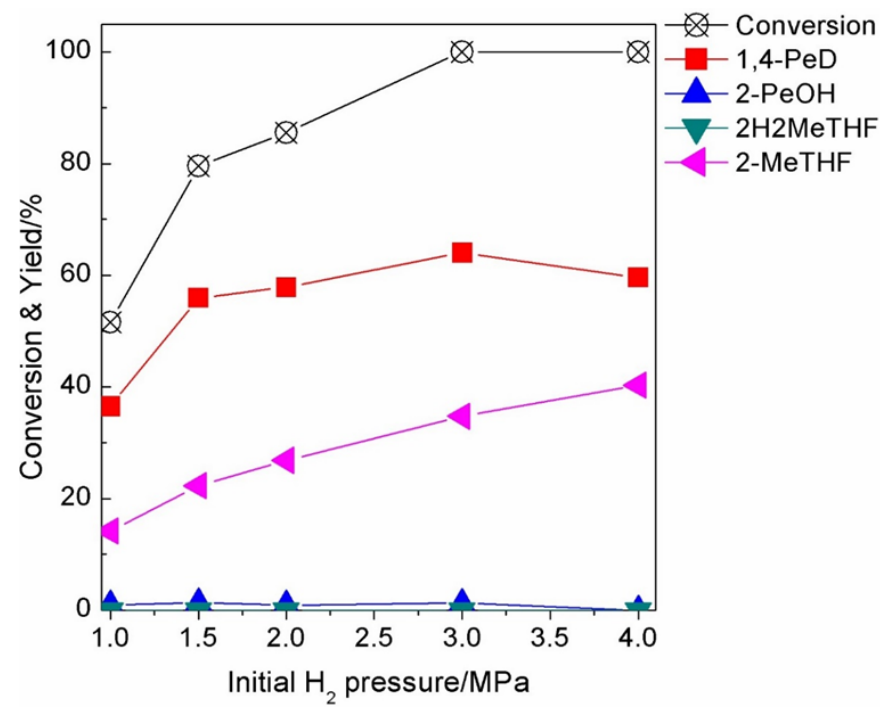

Figure 5. Effect of initial $\mathrm{H}_{2}$ pressure on the conversion and product distribution (yield) in the catalytic reaction of $2-\mathrm{MeF}$ over supported $\mathrm{Ni}$ $\mathrm{Sn}(3.0) / \mathrm{AlOH}$ alloy catalyst. Reaction conditions: catalyst., $50 \mathrm{mg}$; substrate, $1.2 \mathrm{mmol}$; solvent, ethanol/ $\mathrm{H}_{2} \mathrm{O}, 3.5 \mathrm{ml}$ (1.5: 2.0 volume ratio), $433 \mathrm{~K}$, $12 \mathrm{~h}$.

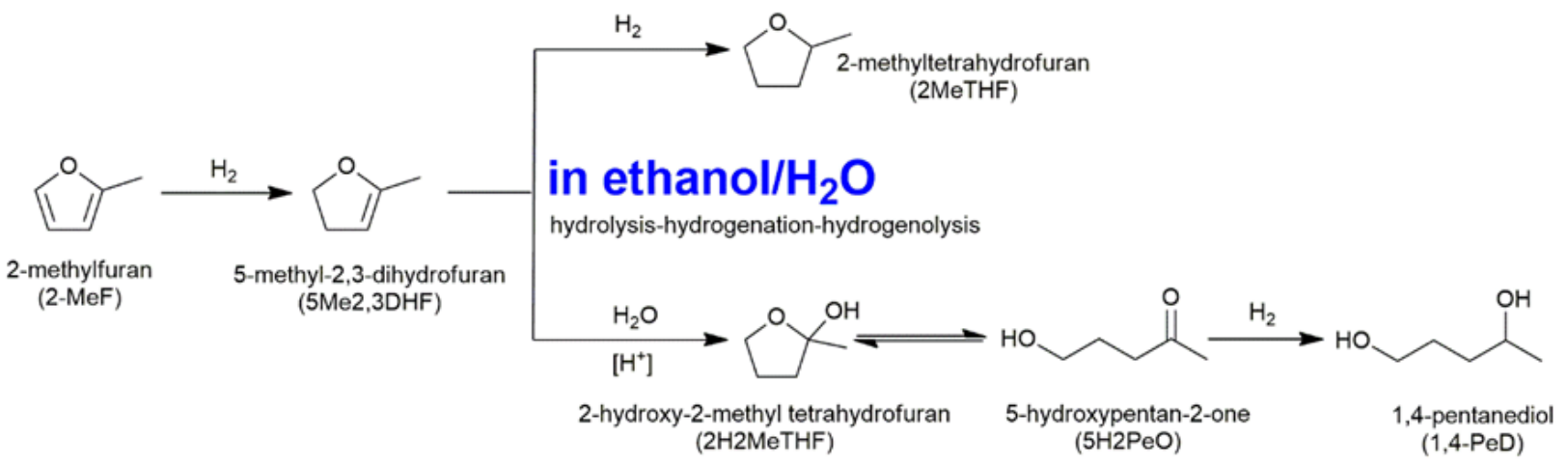

Scheme 1. Possible reaction pathways for the production of 1,4-pentanediol from 2-methylfuran via hydrolysis-hydrogenation over bimetallic Ni-Sn alloy catalysts in an ethanol $/ \mathrm{H}_{2} \mathrm{O}$ solvent mixture. 
further identification of acid types, because it is difficult to distinguish the weak, medium and strong acid sites from such broad desorption peaks. The quantification results are summarized in Table 1. Aluminium hydroxide $(\mathrm{AlOH})$ supported $\mathrm{Ni}-\mathrm{Sn}(3.0)$ has highest acid density among the synthesized catalysts (491 $\mu$ mol.g-1 ${ }^{-1}$ entry 5), $446 \mu \mathrm{mol}^{-1} \mathrm{~g}^{-1}$ for $\mathrm{Ni}-\mathrm{Sn}(3.0) / \gamma$ $\mathrm{Al}_{2} \mathrm{O}_{3}$, and $473 \mu$ mol.g- ${ }^{-1}$ for $\mathrm{Ni}-\mathrm{Sn}(3.0) / \mathrm{AA}$, whereas the lowest acid density was active carbon (AC) supported Ni-Sn(3.0) $\left(83 \mu \mathrm{mol} . \mathrm{g}^{-1}\right.$, entry 6). The acidity of R-Ni/AlOH was similar to the Ni-Sn(3.0)/AA (474 $\mu$ mol.g- ${ }^{-1}$, entry 9$)$ and that of the unmodified Raney ${ }^{\circledR N i}[26]$ and blank $\gamma-\mathrm{Al}_{2} \mathrm{O}_{3}$ [27] was $195 \mathrm{mmol}^{-1}{ }^{-1}$ and 180 $\mu$ mol.g-1, respectively. The acidity emerges mainly from g- $\mathrm{Al}_{2} \mathrm{O}_{3}$ or $\mathrm{AlOH}$ supportss, which depend on the atomic arrangement formed in the bimetallic Ni-Sn alloy crystals [28, 29].

\subsection{Hydrogenation of 2-methylfuran}

\subsubsection{Solvent screening}

First, the catalytic hydrogenation of 2methylfuran over bulk Ni-Sn(3.0) alloy catalyst both in protic (alcohols, 1,4-dioxane, and $\mathrm{H}_{2} \mathrm{O}$ ) and aprotic (acetonitrile and hexane) solvents was carried out, and the results are summarized in Table 2 and the possible reaction pathways are shown in Scheme 1. In alcohol solvents (e.g. methanol, ethanol, and propanol), the conversions of $2-\mathrm{MeF}$ were $28 \%, 10 \%, 56 \%$, and $52 \%$, respectively and produced 2-methyl tetrahydrofuran (2-MeTHF) with $\sim 99 \%$ selec- tivity (entries 1-4). Interestingly, $100 \%$ in conversion of $2-\mathrm{MeF}$ was achieved under the same reaction conditions and the reaction products were distributed to 1,4-pentanediol (1,4-PeD), 2 -pentanol (2-PeOH), 2-hydroxy-2methyltetrahydrofuran (2H2MeTHF), and 2methyl tetrahydrofuran (2-MeTHF) with yields of $15 \%, 3 \%, 4 \%$, and $78 \%$, respectively (entry 5). Since the solubility of $2-\mathrm{MeF}$ in $\mathrm{H}_{2} \mathrm{O}$ solvent is relatively low, a blending solvent of etha$\mathrm{nol} / \mathrm{H}_{2} \mathrm{O}$ or 2-propanol $/ \mathrm{H}_{2} \mathrm{O}$ with volume ratio of 1.5/2.0 was employed as the solvent. In etha$\mathrm{nol} / \mathrm{H}_{2} \mathrm{O}$, the conversion of $2-\mathrm{MeF}$ was $92 \%$ and $49 \%$ yield of $1,4-\mathrm{PeD}$ was obtained (which is higher than that of in $\mathrm{H}_{2} \mathrm{O}$ solvent (increase almost 3 times)), whereas the yield of $2 \mathrm{H} 2 \mathrm{MeTHF}$ remarkably reduced to only $5 \%$ (entry 6). In 2-propanol/ $\mathrm{H}_{2} \mathrm{O}$ and 1,4-dioxane solvents, however, with reducing the amount of undesired product of $2 \mathrm{H} 2 \mathrm{MeTHF}$ to $3 \%$ or $0 \%$, the main product was 2 -MeTHF with compromisely low yield of 1,4-PeD (entries 7 and 8). D

Differences in the product distribution of 2$\mathrm{MeF}$ hydrogenation in alcohols, $\mathrm{H}_{2} \mathrm{O}$, and alcohol/ $/ \mathrm{H}_{2} \mathrm{O}$ may be attributed to the presence of O-bonded water molecules to the $\mathrm{C}$ atom from neighbouring $-\mathrm{CH}_{2} \mathrm{OH}$ group and forming a new water species with one $\mathrm{H}$ atom of water being automatically transferred to the terminal $\mathrm{OH}$ group as it has been evidenced through the $\mathrm{H}_{2}{ }^{18} \mathrm{O}$ isotopic trace experiments combined with the DFT calculations [30,31]. Alternatively, the slow formation of oxidic tin $\left(\mathrm{Sn}^{\mathrm{n}+}\right)$ from metallic tin $\left(\mathrm{Sn}^{0}\right)$ [32,33] that

Table 2. Results of catalytic reaction of $2-\mathrm{MeF}$ over bulk Ni-Sn(3.0) alloy in various protic and aprotic solvents

\begin{tabular}{|c|c|c|c|c|c|c|}
\hline \multirow{2}{*}{ Entry } & \multirow{2}{*}{ Solvent } & \multirow{2}{*}{ Conversion $a / \%$} & \multicolumn{4}{|c|}{ Yield $a / \%$} \\
\hline & & & 1,4-PeD & 2-PeOH & 2H2MeTHF & 2-MeTHF \\
\hline 1 & Methanol & 28 & 0 & 2 & 0 & 26 \\
\hline 2 & Ethanol & 10 & 0 & 1 & 0 & 9 \\
\hline 3 & n-Propanol & 56 & 0 & 1 & 0 & 55 \\
\hline 4 & 2-Propanol & 52 & 0 & 2 & 0 & 50 \\
\hline 5 & $\mathrm{H}_{2} \mathrm{O}$ & 100 & 15 & 3 & 4 & 78 \\
\hline $6^{b}$ & Ethanol $/ \mathrm{H}_{2} \mathrm{O}$ & 92 & 49 & 1 & 5 & 37 \\
\hline $7^{b}$ & 2-Propanol/ $\mathrm{H}_{2} \mathrm{O}$ & 70 & 11 & 3 & 3 & 53 \\
\hline 8 & 1,4-Dioxane & 56 & 7 & 1 & 0 & 48 \\
\hline 9 & Acetonitrile & 21 & 1 & 0 & 0 & 20 \\
\hline 10 & Hexane & 13 & 0 & 0 & 0 & 7 \\
\hline
\end{tabular}

Reaction conditions: catalyst., $44 \mathrm{mg}$; substrate, $1.2 \mathrm{mmol}$; solvent, $3.5 \mathrm{~mL}$ (1.5: 2.0 volume ratio); initial $\mathrm{H}_{2}$ pressure, 3.0 $\mathrm{MPa}, 433 \mathrm{~K}, 12 \mathrm{~h} .{ }^{a}$ Conversion and yields were determined by GC and GC-MS analyses using an internal standard technique. ${ }_{b}$ The solvent was alcohol $/ \mathrm{H}_{2} \mathrm{O}$ or 2-propanol $/ \mathrm{H}_{2} \mathrm{O}$ mixture, $3.5 \mathrm{~mL}$ (1.5 : 2.0 volume ratio). 1,4-PeD = 1,4-pentanediol. 2-PeOH = 2-pentanol. $2 \mathrm{H} 2 \mathrm{MeTHF}=2$-hydroxy-2-methyl tetrahydrofuran. 2 -MeTHF $=2$-methyl tetrahydrofuran. 
generated the acid sites of Ni-Sn alloy and the autoprotolysis of the hydroxylated solvents of $\mathrm{H}_{2} \mathrm{O}$ or alcohol $/ \mathrm{H}_{2} \mathrm{O}$ via proton transfer from $\mathrm{H}_{2} \mathrm{O}$ to the alcohol or 1,4-dioxane [34-36] acidulated the reaction system which synergistically acted for the acid-hydrolysis of furan ring and then subsequent hydrogenation reactions under $\mathrm{H}_{2}$ atmosphere to produce 1,4-PeD [10-14,37]. Hu et al. also suggested that the acid-catalysis and hydrogenation proceeded in parallel in the presence of supported bimetallic Ni-Sn alloy [38]. On the other hand, in aprotic solvents (e.g. acetonitrile and hexane), the catalytic reaction of $2-\mathrm{MeF}$ did not proceed effectively (entries 9 and 10). Therefore, it can be concluded that the suitable solvent for the catalytic reaction of $2-\mathrm{MeF}$ over bimetallic Ni-Sn(3.0) alloy catalyst is a blending ethanol $/ \mathrm{H}_{2} \mathrm{O}$ and therefore, it will be used for further investigation with various catalysts and reaction parameters (initial $\mathrm{H}_{2}$ pressure, reaction temperature, and time profiles).

\subsubsection{Catalyst screening}

To obtain the insight into the role of bimetallic Ni-Sn alloy catalysts in the selective production of 1,4-PeD via hydrolysishydrogenation reaction of $2 \mathrm{-MeF}$, various bimetallic Ni-Sn alloy both bulk and supported catalysts were evaluated, and the results are summarized in Table 3.

First, we carried out the reaction over various bulk Ni-Sn alloy catalysts with different $\mathrm{Ni} / \mathrm{Sn}$ molar ratio at $433 \mathrm{~K}$, initial $\mathrm{H}_{2}$ pressure of $3.0 \mathrm{MPa}$, in blending solvent ethanol/ $\mathrm{H}_{2} \mathrm{O}$ and reaction time of $6 \mathrm{~h}$ or $12 \mathrm{~h}$. By using $\mathrm{Ni}-\mathrm{Sn}(0.75)$ alloy, the conversion of $2-\mathrm{MeF}$ was only $17 \%$ and produced $9 \% 2$-MeTHF (entry 1 ),

Table 3. Results of catalytic reaction of 2-methylfuran over various both bulk and supported Ni-Sn alloys in blending solvent of ethanol/ $\mathrm{H}_{2} \mathrm{O}$

\begin{tabular}{|c|c|c|c|c|c|c|}
\hline \multirow{2}{*}{ Entry } & \multirow{2}{*}{ Catalysts $^{a}$} & \multirow{2}{*}{ Conversion $\mathrm{b} / \%$} & \multicolumn{4}{|c|}{ Yield $/ \%$} \\
\hline & & & 1,4-PeD & $2-\mathrm{PeOH}$ & 2H2MeTHF & 2-MeTHF \\
\hline 1 & Bulk Ni-Sn(0.75) & 17 & 0 & 0 & 0 & 9 \\
\hline 2 & Bulk Ni-Sn(1.0) & 39 & 0 & 0 & 0 & 21 \\
\hline $3^{c}$ & Bulk Ni-Sn(1.5) & 63 & 36 & 4 & 2 & 21 \\
\hline 4 & Bulk Ni-Sn(1.5) & 94 & 49 & 1 & 7 & 38 \\
\hline 5 & Bulk Ni-Sn(2.0) & 49 & 0 & 0 & 0 & 49 \\
\hline $6^{\mathrm{c}}$ & Bulk Ni-Sn(3.0) & 68 & 48 & 2 & 0 & 18 \\
\hline 7 & Bulk Ni-Sn(3.0) & 92 & 49 & 1 & 5 & 37 \\
\hline $8^{\mathrm{d}}$ & Bulk Ni-Sn(3.0) & 100 & 33 & 5 & 1 & 61 \\
\hline $9 \mathrm{e}$ & $\mathrm{Ni}-\mathrm{Sn}(3.0) / \mathrm{AA}$ & 88 & 31 & 3 & 3 & 51 \\
\hline 10 & $\mathrm{Ni}-\mathrm{Sn}(3.0) / \mathrm{AlOH}$ & 100 & 64 & 1 & 0 & 35 \\
\hline 11 & $\mathrm{Ni}-\mathrm{Sn}(3.0) / \gamma-\mathrm{Al}_{2} \mathrm{O}_{3}$ & 100 & 51 & 3 & 0 & 46 \\
\hline 12 & $\mathrm{Ni}-\mathrm{Sn}(3.0) / \mathrm{AC}$ & 100 & 43 & 6 & 4 & 47 \\
\hline 13 & $\mathrm{Ni}-\mathrm{Sn}(3.0) / \mathrm{SiO}_{2}$ & 100 & 35 & 6 & 5 & 55 \\
\hline 14 & $\mathrm{Ni}-\mathrm{Sn}(1.5) / \mathrm{AlOH}$ & 75 & 39 & 0 & 1 & 35 \\
\hline 15 & $\mathrm{Ni}-\mathrm{Sn}(1.5) / \gamma-\mathrm{Al}_{2} \mathrm{O}_{3}$ & 69 & 47 & 0 & 0 & 22 \\
\hline 16 & $\mathrm{Ni}-\mathrm{Sn}(1.5) / \mathrm{AC}$ & 57 & 18 & 2 & 0 & 37 \\
\hline 17 & $\mathrm{Ni}-\mathrm{Sn}(1.5) / \mathrm{SiO}_{2}$ & 51 & 21 & 0 & 0 & 30 \\
\hline 18 & $\mathrm{R}-\mathrm{Ni} / \mathrm{AlOH}$ & 100 & 31 & 3 & 0 & 66 \\
\hline 19 & Raney®Ni & 100 & 0 & 0 & 0 & $>99$ \\
\hline 20 & $\mathrm{Pd} / \mathrm{C}(5 \mathrm{wt} \% \mathrm{Pd})$ & 100 & 0 & 0 & 0 & $>99$ \\
\hline
\end{tabular}

Reaction conditions: catalyst., $50 \mathrm{mg}$; substrate, $1.2 \mathrm{mmol}$; solvent, ethanol $/ \mathrm{H}_{2} \mathrm{O}, 3.5 \mathrm{~mL}\left(1.5: 2.0\right.$ volume ratio); initial $\mathrm{H}_{2}$ pressure, 3.0 MPa, $433 \mathrm{~K}, 12 \mathrm{~h}$. ${ }^{a}$ Values in the parentheses are the Ni/Sn molar ratio, determined by ICP-AES analysis. ${ }^{b}$ Conversion and yields were determined by GC and GC-MS analyses using an internal standard technique. ${ }^{c}$ Reaction time was 6 h. $d$ Reaction time was 19 h. ${ }^{e}$ The catalyst was synthesized from Raney nickel supported on aluminium hydroxide and tin (II) dihydrate via hydrothermal at $425 \mathrm{~K}$ for $2 \mathrm{~h}$, dried at room temperature, then followed by $\mathrm{H}_{2}$ reduction at $673 \mathrm{~K}$ for $1.5 \mathrm{~h}$ according to reference [16,17]. 1,4-PeD $=1,4$-pentanediol. 2-PeOH $=2$-pentanol. 2H2MeTHF $=2$-hydroxy-2-methyl tetrahydrofuran. 2-MeTHF = 2-methyl tetrahydrofuran. 
while over Ni-Sn(1.0) alloy was $39 \%$ conversion with $21 \%$ yield of 2-MeTHF (entry 2). Over $\mathrm{Ni}-\mathrm{Sn}(1.5)$ alloy, $63 \%$ of $2-\mathrm{MeF}$ was converted after a reaction time of $6 \mathrm{~h}$ and the main products were $1,4-\mathrm{PeD}$ and 2 -MeTHF with yields of $36 \%$ and $21 \%$, respectively (entry 3 ). At a reaction time of $12 \mathrm{~h}$, the conversion of $2-\mathrm{MeF}$ increased to $94 \%$ and yields of $1,4-\mathrm{PeD}, 2-\mathrm{MeF}$, and $2 \mathrm{H} 2 \mathrm{MeTHF}$ also increased slightly to $49 \%$, $38 \%$, and $7 \%$, respectively (entry 4). Over $\mathrm{Ni}-\mathrm{Sn}(2.0)$ alloy, the conversion of $2-\mathrm{MeF}$ was $49 \%$ and yielded only 2 -MeTHF ( $49 \%$ in yield, entry 5). Interestingly, by using Ni-Sn(3.0) catalyst, $68 \%$ of $2-\mathrm{MeF}$ was converted and afforded of $1,4-\mathrm{PeD}$ ( $48 \%$ yield), $2-\mathrm{PeOH}$ ( $2 \%$ yield), and 2 -MeTHF (18\% yield) after a reaction time of $6 \mathrm{~h}$ (entry 6). When a reaction time was prolonged to $12 \mathrm{~h}$, the conversion of $2-\mathrm{MeF}$ increased to $92 \%$ whereas the yield of $1,4-\mathrm{PeD}$ was almost constant to $49 \%$ (entry 7 ). However, at $100 \%$ conversion of $2-\mathrm{MeF}, 1,4-\mathrm{PeD}$ yield decreased significantly to $33 \%$ while 2 -MeTHF yield increased almost twice (61\%) after a reaction time was extended to $19 \mathrm{~h}$ (entry 8). These results indicated that over hydrogenation of furan ring to produce 2-MeTHF occurred as it had been reported previously [10]. Therefore, it can be concluded that among the synthesized bimetallic Ni-Sn alloy catalysts, Ni-Sn alloy that consist of $\mathrm{Ni}_{3} \mathrm{Sn}$ and $\mathrm{Ni}_{3} \mathrm{Sn}_{2}$ alloy species are active for the hydrolysis-hydrogenation of $2-\mathrm{MeF}$ to $1,4-\mathrm{PeD}$.

The catalytic reaction of supported $\mathrm{Ni}-\mathrm{Sn}(3.0)$ and Ni-Sn(1.5) on various supports that having a Brönsted acidity (i.e. amorphous alumina, $\gamma$-alumina, aluminium hydroxide, and active carbon) under the same reaction conditions and the results are also investigated and summarized in Table 3. In the case of supported Ni-Sn(3.0)/AA (AA = amorphous alumina) catalyst which was synthesized according to the previously published works [16,17], a moderate yield of $1,4-\mathrm{PeD}(31 \%)$ was obtained at $88 \%$ conversion of $2-\mathrm{MeF}$ under the same reaction conditions (entry 9). Interestingly, over aluminium hydroxide $(\mathrm{AlOH})$ and $\gamma-\mathrm{Al}_{2} \mathrm{O}_{3}$ supported Ni-Sn(3.0) alloy catalysts, high yields of $1,4-\mathrm{PeD}(64 \%$ and $51 \%$, respectively) were achieved (entries 10 and 11). To the best of our knowledge, these results are the highest yield of 1,4-PeD from catalytic conversion of $2-\mathrm{MeF}$ without the addition of formic acid or acetic acid glacial as it had been reported previously $[10,39]$. It can be also observed that aluminium hydroxide (AlOH) and $\gamma-\mathrm{Al}_{2} \mathrm{O}_{3}$ supported $\mathrm{Ni}-\mathrm{Sn}(3.0)$ catalysts not only enhanced the yield of 1,4-PeD but also reduced the amount of undesired product of $2 \mathrm{H} 2 \mathrm{MeTHF}$. These results can be attributed to the fact that aluminium hydroxide $(\mathrm{AlOH})$ and $\gamma-\mathrm{Al}_{2} \mathrm{O}_{3}$ supports have relatively high surface acidity as indicated by the $\mathrm{NH}_{3}$-TPD measurements (Figure 2 and Table 2). While over $\mathrm{AC}$ and $\mathrm{SiO}_{2}$ supported Ni-Sn(3.0) alloy catalysts afforded $35 \%$ and $43 \%$ 1,4-PeD in yield with remained $2 \mathrm{H} 2 \mathrm{MeTHF}$ was $4 \%$ and $5 \%$, respectively (entries 12 and 13). In the case of supported $\mathrm{Ni}-\mathrm{Sn}(1.5)$ alloy catalysts, $\gamma-\mathrm{Al}_{2} \mathrm{O}_{3}$ supported Ni-Sn(1.5) exhibited the highest yield of 1,4$\mathrm{PeD}$ (47\%) among the various supports (entry 14-17). The enhancement of desired product of 1,4-PeD over $\mathrm{AlOH}$ or $\gamma-\mathrm{Al}_{2} \mathrm{O}_{3}$ supported Ni$\mathrm{Sn}(3.0)$ and Ni-Sn(1.5) alloy catalysts can be attributed to the nature of surface acidity catalysts. $\mathrm{NH}_{3}$-TPD measurements show the differences in the surface acidity (e.g., part of strong acid, $>923 \mathrm{~K}$ ) between $\mathrm{AlOH}$ or $\gamma-\mathrm{Al}_{2} \mathrm{O}_{3}$ and $\mathrm{AC}$ supports (Figure 4 and Table 1 ). The strong acid site may able to interact with $\mathrm{C}=\mathrm{C}$ bond of furan ring, protonated, and then hydrolysed in presence of ethanol/ $\mathrm{H}_{2} \mathrm{O}$ [40-43]. Note to be important that over $\mathrm{AlOH}$ or $\gamma-\mathrm{Al}_{2} \mathrm{O}_{3}$ supported Ni-Sn(3.0) catalysts, no side polymerization product was observed within the reactions. In addition, Raney Ni supported on aluminium hydroxide (R-Ni/AlOH) catalyst also provided $31 \%$ in yield of $1,4-\mathrm{PeD}$ (entry 18 ), while a commercially available Raney® $\mathrm{Ni}$ and $5 \% \mathrm{wt} \mathrm{Pd} / \mathrm{C}$ catalyst produced $>99 \% 2$-MeTHF in yields without the formation of $1,4-\mathrm{PeD}$ or $2-\mathrm{PeOH}$ products (entries 19 and 20).

\subsubsection{Effect of initial $\mathrm{H}_{2}$ pressure}

The effect initial $\mathrm{H}_{2}$ pressure on the conversion of $2-\mathrm{MeF}$ and yield of $1,4-\mathrm{PeD}$ over $\mathrm{Ni}$ $\mathrm{Sn}(3.0) / \mathrm{AlOH}$ catalyst was evaluated at the range of 1.0-4.0 $\mathrm{MPa}$ and the results are shown in Figure 5. 2-MeF conversion and 2 -MeTHF yield gradually increased as the initial $\mathrm{H}_{2}$ pressure increased to reach a maximum conversion $(100 \%)$ at $3.0 \mathrm{MPa}$, meanwhile 1,4-PeD yield increased smoothly to maximum (64\%) between 1.5 and $3.0 \mathrm{MPa}$, then slightly decreased to $60 \%$ at initial $\mathrm{H}_{2}$ pressure of 4.0 $\mathrm{MPa}$.

\subsubsection{Effect of reaction temperature}

The influence of reaction temperature on the 2-MeTF conversion and yields of 1,4-PeD and 2-MeTHF over Ni-Sn(3.0)/AlOH alloy catalyst is shown in Figure 6. At $373 \mathrm{~K}$, the conversion of 2-MeTF was $69 \%$ and yields of 2 -MeTHF and $2 \mathrm{H} 2 \mathrm{MeTHF}$ were $31 \%$ and $38 \%$, 
respectively. Since the C-O bond hydrogenolysis is enhanced at higher temperatures in comparison to the hydrogenation of the $\mathrm{C}=\mathrm{C}$ bonds, lower temperatures favour the formation of 2-MeTHF and 2H2MeTHF.

While higher temperatures led to a higher 1,4-PeD selectivity, they also promoted the side reactions that not depend on the catalyst and resulted in a slightly decrease in $1,4-\mathrm{PeD}$ selectivity in higher temperatures. The yield of $2 \mathrm{H} 2 \mathrm{MeTHF}$ drastically decreased as the reaction temperature increased, and then it totally disappeared over $433 \mathrm{~K}$ to form $1,4-\mathrm{PeD}$ as the final product. However, yield of 2-MeTHF was almost constant as a result of over hydrogenation of furan ring at the temperature ranges. The highest yield of 1,4-PeD (64\%) was achieved at $433 \mathrm{~K}$. Therefore, we conclude that the optimised reaction temperature for the 1,4-PeD production from $2-\mathrm{MeTF}$ using $\mathrm{Ni}$ $\mathrm{Sn}(3.0) / \mathrm{AlOH}$ was $433 \mathrm{~K}$.

\subsubsection{Kinetics}

The kinetic profiles of catalyitic reaction of 2-MeTF over supported Ni-Sn(3.0)/AlOH alloy catalyst are shown in Figure 7. It can be observed that 2-MeTF conversion increased gradually as a function of reaction time and achieved after a reaction time of $12 \mathrm{~h}$. At earlier time, the products were dominated by $2 \mathrm{H} 2 \mathrm{MeTHF}$ with maximum $21 \%$ in yield (after $2 \mathrm{~h}$ ) then decreased gradually as the reaction time prolonged to reach almost constant after

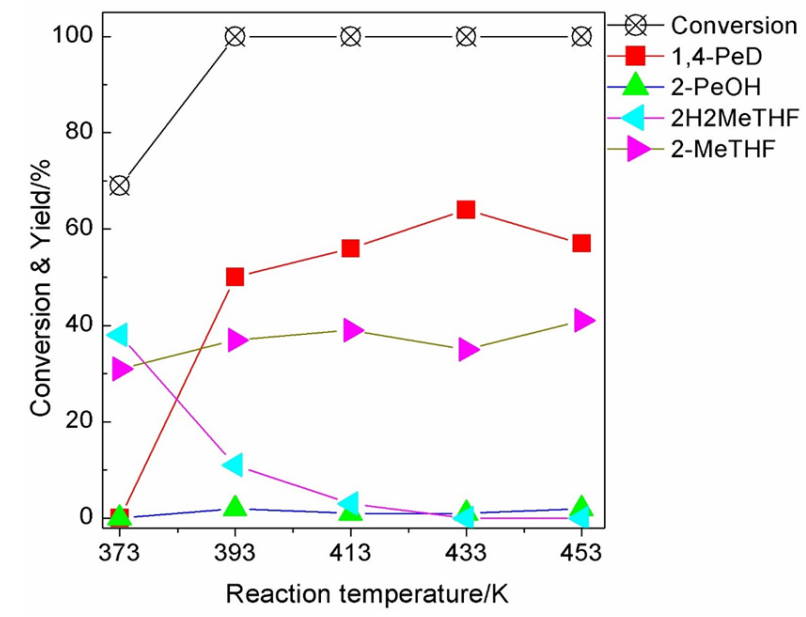

Figure 6. Effect of reaction temperature on the conversion and product distribution (yield) in the catalytic reaction of $2-\mathrm{MeF}$ over supported $\mathrm{Ni}$ $\mathrm{Sn}(3.0) / \mathrm{AlOH}$ alloy catalyst. Reaction conditions: catalyst., $50 \mathrm{mg}$; substrate, $1.2 \mathrm{mmol}$; solvent, ethanol $/ \mathrm{H}_{2} \mathrm{O}, 3.5 \mathrm{~mL}$ (1.5: 2.0 volume ratio); initial $\mathrm{H}_{2}$ pressure, 3.0 $\mathrm{MPa}, 12 \mathrm{~h}$. reaction time was extended up to $16 \mathrm{~h}$. Meanwhile the amount of 2-MeTHF and $1,4-\mathrm{PeD}$ was almost equal indicating the hydrogenation and hydrolysis of double bond of furang ring occurred in parallel as indicated in the previous reports [10,14,39-42]. As the reaction times were prolonged, yield $1,4-\mathrm{PeD}$ also increased smoothly to reach maximum $64 \%$ in yield after $12 \mathrm{~h}$ and then gradually decreased after a reaction time of $14 \mathrm{~h}$. On the other hand, yield of 2-MeTHF increased gradually after the reaction time was extended up to $16 \mathrm{~h}$.

Although the remained $2 \mathrm{H} 2 \mathrm{MeTHF}$ can be reduced or yield of 1,4-PeD can be enhanced by adding a homogeneous acid additive (e.g. formic acid or acetic glacial), the use of additives is not desirable and should be avoided if possible, as suggested by Schniepp et al.[10] and Leuck et al. [39] Especially at relatively higher temperature and initial $\mathrm{H}_{2}$ pressure, the formation of $1,4-\mathrm{PeD}$ are strongly influenced by both those parameters as shown in Figure 5 and Figure 6. Therefore, we conclude that our $\mathrm{AlOH}$ or $\gamma-\mathrm{Al}_{2} \mathrm{O}_{3}$ supported $\mathrm{Ni}-\mathrm{Sn}(3.0)$ and $\mathrm{Ni}-$ $\mathrm{Sn}(1.5)$ alloy catalysts are suitable for the hydrolysis-hydrogenation reaction of $2-\mathrm{MeF}$ to produce a high valuable $1,4-\mathrm{PeD}$ (with yield up to $64 \%$ ) product under milder reaction conditions [43].

\subsubsection{Reusability test}

A reusability test was performed on the $\mathrm{Ni}$ $\mathrm{Sn}(3.0) / \mathrm{AlOH}$ catalyst, and the results are summarized in Table 4.

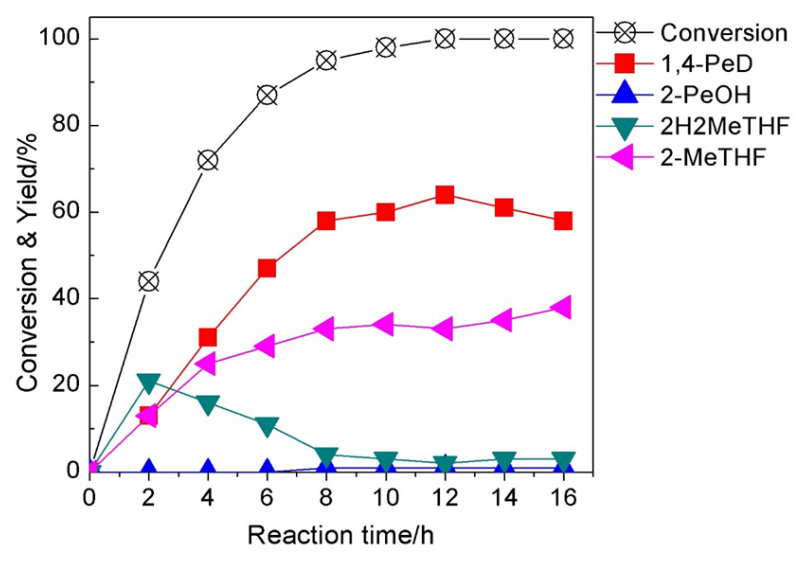

Figure 7. Kinetic profiles of catalytic conversion of $2-\mathrm{MeF}$ in presence of supported Ni-Sn(3.0)/AlOH catalyst. Reaction conditions: catalyst., $50 \mathrm{mg}$; substrate, $1.2 \mathrm{mmol}$; solvent, ethanol $/ \mathrm{H}_{2} \mathrm{O}, 3.5 \mathrm{~mL}$ (1.5: 2.0 volume ratio), $433 \mathrm{~K}$, initial $\mathrm{H}_{2}$ pressure of $3.0 \mathrm{MPa}$. 
The used Ni-Sn(3.0)/AlOH catalyst was easily separated by either simple centrifugation or filtration after the reaction and dried under vacuum for overnight prior to use for the next reaction. The activity of the catalyst decreased as well as the yield of $1,4-\mathrm{PeD}$ both the catalytic system. In the case of Ni-Sn(3.0)/AlOH system, the amount of $\mathrm{Ni}, \mathrm{Sn}$, and $\mathrm{Al}$ that leached into the reaction solution was $0.58 \mathrm{~mol} \%, 1.3$ $\mathrm{mol} \%$, and $1.9 \mathrm{~mol} \%$ after the second run, respectively. Therefore, the treatment of the recovered Ni-Sn(3.0)/AlOH catalyst (after the second runs) with $\mathrm{H}_{2}$ at $673 \mathrm{~K}$ for $1 \mathrm{~h}$ is required to restore the catalyst's original activity and selectivity.

\section{Conclusion}

We demonstrate that the catalytic hydrogenation of 2-methylfuran (2-MeF) in presence of bimetallic Ni-based alloy catalysts produced selectively 1,4-pentanediol (1,4-PeD) in an ethanol $/ \mathrm{H}_{2} \mathrm{O}$ solvent mixture. In $\mathrm{H}_{2} \mathrm{O}$, blended ethanol $/ \mathrm{H}_{2} \mathrm{O}$, or 2-propanol $/ \mathrm{H}_{2} \mathrm{O}$, the hydrogenation of $2-\mathrm{MeF}$ was proceeded effectively. The acid density of aluminium hydroxide $(\mathrm{AlOH})$ or $\gamma-\mathrm{Al}_{2} \mathrm{O}_{3}$ supported Ni-Sn(3.0) alloy catalysts may play a key role during the hydrolysishydrogenation of 2-methylfuran to afford $1,4-\mathrm{PeD}$ with $64 \%$ in yields at $433 \mathrm{~K}, 3.0 \mathrm{MPa}$ of $\mathrm{H}_{2}$ within $12 \mathrm{~h}$. Ni-Sn(3.0)/AlOH was found to be reusable and the treatment of the recovered Ni-Sn(3.0)/AlOH catalyst (after the second runs) with $\mathrm{H}_{2}$ at $673 \mathrm{~K}$ for $1 \mathrm{~h}$ restored the catalyst's original activity and selectivity.

\section{Acknowledgements}

This work was financially supported by JSPS-DGHE through Joint Bilateral Research Project FY 2014-2017, KLN and International Publication Project of DGHE FY 2015-2016 under grant number of DIPA-02304.1.673453/2016, and Penelitian Berbasis Kompetensi (PBK) FY 2017-2018 under grant number of DIPA-042.06-1.401516/2018 from
Ministry of Research, Technology, and Higher Education, Indonesian Government. Authors would also like extent the gratitude to Assoc. Prof. Takashi Kojima for kind help in TEM and SEM measurements.

\section{References}

[1] Dutta, S., Mascal, M. (2014). Novel pathways to 2,5-dimethylfuran via biomass-derived 5(chloromethyl)furfural. ChemSusChem. 7: 3028-3030.

[2] Mariscal, R., Maireles-Torres, P., Ojeda, M., Sádaba, I., Granados, M.L. (2016). Furfural: a renewable and versatile platform molecule for the synthesis of chemicals and fuels, Energy Environmental Sciences. 9: 1144-1189.

[3] Xing, R., Qi, W., Huber, G.W. (2011). Production of furfural and carboxylic acids from waste aqueous hemicellulose solutions from the pulp and paper and cellulosic ethanol industries. Energy Environmental Sciences. 4: 21932205.

[4] Burnette, L.W., Johns, I.B., Holdren, R.F., Hixon, R.M. (1948). Production of 2methylfuran by vapor-phase hydrogenation of furfural. Industrial Engineering Chemistry. 40(3): 502-505.

[5] Kang, J., Liang, X., Gulliants, V.V. (2016). Selective hydrogenation of 2-methylfuran and 2,5-dimethylfuran over atomic layer deposited Pt catalysts on multi-walled carbon nanotube and alumina supports. ChemCatChem. 9(2): 282-286.

[6] Aliaga, C., Tsung, C.-K., Alayoglu, S., Komvopoulos, K., Yang, P., Somorjai, G.A. (2011). Sum frequency generation vibrational spectroscopy and kinetic study of 2methylfuran and 2,5-dimethylfuran hydrogenation over $7 \mathrm{~nm}$ platinum cubic nanoparticles. Journal Physical Chemistry C. 115: 8104-8109.

[7] Kang, J., Vonderheide, A., Guliants, V.V. (2015). Deuterium-labeling study of the hydrogenation of 2-methylfuran and 2,5-

Table 4. Results of the reusability test for Ni-Sn(3.0)/AlOH in the hydrogenation of 2-MeTF

\begin{tabular}{|c|c|c|c|c|c|c|}
\hline Run & 1 & 2 & $3^{a}$ & \multicolumn{3}{|c|}{ Amount of leached metals ${ }^{b}(\% \mathrm{~mol})$} \\
\hline Conversion ${ }^{c}(\%)$ & 100 & 78 & 100 & $\mathrm{Ni}$ & $\mathrm{Sn}$ & $\mathrm{Al}$ \\
\hline Yieldc (\%) & 64 & 57 & 67 & 0.58 & 1.30 & 1.90 \\
\hline
\end{tabular}

Reaction conditions: catalyst., $50 \mathrm{mg}$; substrate, $1.2 \mathrm{mmol}$; solvent, ethanol/ $\mathrm{H}_{2} \mathrm{O}, 3.5 \mathrm{~mL}$ (1.5: 2.0 volume ratio); initial $\mathrm{H}_{2}$ pressure, $3.0 \mathrm{MPa}, 433 \mathrm{~K}, 12 \mathrm{~h}$. ${ }^{a}$ The recovered Ni-Sn(3.0)/AlOH catalyst was reduced by $\mathrm{H}_{2}$ at $673 \mathrm{~K}$ for $1 \mathrm{~h}$ prior to the next reaction. $b$ The amount of leached metals was determined by ICP-AES from the reaction mixture after the first reaction run. ${ }^{c}$ Conversion of $2-\mathrm{MeF}$ and yield of $1,4-\mathrm{PeD}$ were determined by GC using an internal standard technique. 
dimethylfuran over carbon-supported noble metal catalysts. ChemSusChem. 8: 3044-3047.

[8] Tomishige, K., Nakagawa, Y., Tamura, M. (2017). Selective hydrogenolysis and hydrogenation using metal catalysts directly modified with metal oxide species. Green Chemistry. 19: 2876-2924.

[9] Werle, P., Morawietz, M., Lundmark, S., Sörensen, K., Karvinen, E., Lehtonen, J. (2008). Alcohols, Polyhydric. Ullmann's Encyclopedia of Industrial Chemistry; Wiley-VCH Verlag GmbH \& Co.

[10] Schniepp, L.E., Geller, H.H, Von Korff, R.W. (1947). The preparation of acetopropyl alcohol and 1,4-pentanediol from 2methylfuran. Journal of American Chemical Society. 69: 672-674.

[11] Whiting, J.E., Edward, J.T. (1971). RingChain Tautomerism of Hydroxyketones. Canadian Journal of Chemistry. 49(23): 37993806.

[12] Soós, J. (1987). Mechanism of the formation of 5-hydroxy-2-pentanone from 2-methylfuran in alkaline media. Reaction Kinetics and Catalysis Letters. 34(2): 333-337.

[13] Zolotarev, N.S., Latvis, P.P., Buimov, A.A., Sirotenko, V.I., Lisnyanskii, I.M., Novikova, K.E., Bogatyrev, Yu.V., Zhhanovich, E.S. (1972). A study of the process of preparing gacetopropyl alcohol from furfural. KhimikoFarmasevticheskii Zhurnal. 6(3): 52-56.

[14] Perchenok, M.Sh., Sevchenko, V.S., Komarov, V.M., Zavel`skii, D.Z. (1976). Continous method of obtaining 3-acetylpropan-1-ol from methylfuran. Khimiko-Farmasevticheskii Zhurnal. 10(2): 91-96.

[15] Rodiansono, R., Khairi, S., Hara, T., Ichikuni, N., Shimazu, S. (2012). Highly efficient and selective hydrogenation of unsaturated carbonyl compounds using Ni-Sn alloy catalysts. Catalysis Science \& Technology. 2: 2139-2145.

[16] Rodiansono, R., Hara, T., Ichikuni, N., Shimazu, S. (2012). A novel preparation method of Ni--Sn alloy catalysts supported on aluminium hydroxide: Application to chemoselective hydrogenation of unsaturated carbonyl compounds. Chemistry Letters. 41: 769-771.

[17] Rodiansono, R., Astuti, M.D., Hara, T., Ichikuni, N., Shimazu, S. (2016). Efficient hydrogenation of levulinic acid in water using a supported Ni-Sn alloy on aluminium hydroxide catalysts. Catal. Sci. Technol. 6: 29552961.

[18] Rodiansono, R., Ghofur, A., Astuti, M.D., Sembiring, K.C. (2015). Catalytic hydrogenation of levulinic acid in water into $\mathrm{g}$ valerolactone over bulk structure of inexpen- sive intermetallic Ni-Sn alloy catalysts, Bulletin Chemical Reaction Engineering \& Catalysis.10(2): 192-200.

[19] Lowell, S., Shields, J. E., Thomas, M.A., Thommes, M. (2004) Characterization of porous solids and powders: surface area, pore size and density, Kluwer Academic Publishers, Netherlands, Chapter 8.

[20] Bartholomew, C.H., Pannel, R.B. (1980). The stoichiometry of hydrogen and carbon monoxide chemisorption on alumina- and silicasupported nickel. Journal of Catalysis. 65: 390-401.

[21] SDBS Web:

http://riodb01.ibase.aist.go.jp/sdbs/ (National Institute of Advanced Science and Technology, 2018. 10.03)

[22] Powder diffraction file, JCPDS-International center for diffraction data (ICDDS), 1991.

[23] Rietica Web: http://www.rietica.org/links.htm/, MultiRietveld Analysis Program LH-Riet 7.200 on the Rietica software, 2018.01.10.

[24] Sweegers, C., de Coninck, H.C., Meekes, H., van Enckevort, W.J.P., Hiralal, I.D.K., Rijkeboer, A. (2001). Morphology, evolution and other characteristics of gibbsite crystals grown from pure and impure aqueous sodium aluminate solutions. Journal of Crystall Growth. 233: 567-582.

[25] Sweegers, C., de Coninck, H.C., Meekes, H., van Enckevort, W.J.P., Hiralal, I.D.K., Rijkeboer, A. (2002). Surface topography of gibbsite crystals grown from aqueous sodium aluminate solutions. Applied Surface Science. 187: 218-234.

[26] Miranda, B.C., Chimentao, R.J., Santos, J.B.O., Gispert-Guirado, F., Llorca, J., Medina, F., Bonillo, F.L., Sueiras, J.E. (2014). Conversion of glycerol over $10 \% \mathrm{Ni} / \mathrm{Y}^{-}$ $\mathrm{Al}_{2} \mathrm{O}_{3}$ catalyst. Applied Catalysis B: Environment. 147: 464-480.

[27] Liu, C., Hou, R., Wang, T. (2015). Role of acid sites and surface hydroxyl groups in isophthalonitrile hydrogenation catalyzed by supported Ni-Co catalysts. RSC Advances. 5: 26465-26474.

[28] Onda, A., Komatsu, T., Yashima, T. (2003). Characterizations and catalytic properties of fine particles of $\mathrm{Ni}-\mathrm{Sn}$ intermetallic compounds supported on $\mathrm{SiO}_{2}$. Journal of Catalysis. 221: 378-385.

[29] Hlukhyy, V., Raif, F., Clauss, P., Fässler, T.F. (2008). Polar intermetallic compounds as catalysts for hydrogenation reactions: Synthesis, structures, bonding, and catalytic properties of $\mathrm{Ca}_{1-\mathrm{x}} \mathrm{Sr}_{\mathrm{x}} \mathrm{Ni}_{4} \mathrm{Sn}_{2}(\mathrm{x}=0.0,0.5,1.0)$ and cata- 
lytic properties of $\mathrm{Ni}_{3} \mathrm{Sn}$ and $\mathrm{Ni}_{3} \mathrm{Sn}_{2}$. Chemistry European Journal. 14: 3737-3744.

[30] Zhang, B., Zhu, Y., Ding, G., Zheng, H., Li, Y. (2012). Selective conversion of furfuryl alcohol to 1,2-pentanediol over a $\mathrm{Ru} / \mathrm{MnO}_{x}$ catalyst in aqueous phase. Green Chemistry. 14: 3402-3409.

[31] Ma, R., Wu, X.P., Tong, T., Shao, Z.J., Wang, Y., Liu, X., Xia, Q., Gong, Xu. Q. (2017). The critical role of water in the ring opening of furfural alcohol to 1,2-pentanediol. ACS Catalysis. 7: 333-337.

[32] Sordelli, L., Psaro, R., Vlaic, G., Cepparo, A., Recchia, S., Fusi, A., Zanoni, R. (1999). EXAFS studies of supported Rh-Sn catalysts for citral hydrogenation. Journal of Catalysis. 182: $186-198$.

[33] Margitfalvi, J.L., Tompos, A., Kolosova, I., Valyon, J. (1998). Reaction induced selectivity improvement in the hydrogenation of crotonaldehyde over $\mathrm{Sn}-\mathrm{Pt} / \mathrm{SiO}_{2}$ catalysts. Journal of Catalysis. 174: 246-249.

[34] Eastman, E.D., Robinson, P. (1928). Equilibrium in the reactions of tin with water vapor and carbon dioxide. Journal of American Chemical Society. 50(4): 1106-1114.

[35] Gutbezahl, B., Grunwald, E. (1953). The acidity and basicity scale in the system ethanolwater. The evaluation of degenerate activity coefficients for single ions. Journal of American Chemical Society. 75(3): 565-574.

[36] Roses, M., Rafols, C., Bosch, E. (1993). Autoprotolysis in aqueous organic solvent mixtures. Analytical Chemistry. 65: 2294-2299.
[37] Piancatelli, G., D’Auria, M., D’Onofrio, F. (1994). Synthesis of 1,4-dicarbonyl compounds and cyclopentenone from furan. Synthesis. 867-889.

[38] Hu, X., Westerhof, R.J.M., Wu, L., Dong, D., Li, C.Z. (2015). Upgrading biomass-derived furans via acid-catalysis/hydrogenation: The remarkable difference between water and methanol as the solvent. Green Chemistry. 17: 219224.

[39] Leuck, G.J., Pokorny, J., Peters, F.N. (1937). Preparation of polyhydroxy compounds from furan compounds. U.S. Patents. 2,097,493.

[40] Götz, D., Lucas, M., Claus, P. (2016). C-O bond hydrogenolysis vs. $\mathrm{C}=\mathrm{C}$ group hydrogenation of furfuryl alcohol: Towards sustainable synthesis of 1,2-pentanediol. Reaction Chemistry Engineering. 1: 161-164.

[41] Marakatti, V.S., Arora, N., Rai, S., Sarma, S.Ch., Peter, S.C. (2018). Understanding the role of atomic ordering in the crystal structures of $\mathrm{Ni}_{\mathrm{x}} \mathrm{Sn}_{\mathrm{y}}$ toward efficient vapor phase furfural hydrogenation. ACS Sustainable Chemistry Engineering. 6(6): 7325-7338.

[42] Liu, F., Liu, Q., Xu, J., Li, L., Cui, Y.-T., Lang, R., Li, L., Su, Y., Miao, S., Sun, H., Qiao, B., Wang, A., Jerome, F., Zhang, T. 2018. Catalytic cascade conversion of furfural to 1,4pentanediol in a single reactor. Green Chemistry. 20: 1770-1776.

[43] Rodiansono, R., Astuti, M.D., Hara, T., Ichikuni, N., Shimazu, S. (2019). One-pot selective conversion of C5-furan into 1,4pentanediol over bulk Ni-Sn alloy catalysts in an ethanol $/ \mathrm{H}_{2} \mathrm{O}$ solvent mixture. Green Chemistry, 21: 2307-2315 